\title{
Sperm imprinting integrity in seminoma patients?
}

Céline Bruno ${ }^{1,2}$, Oxana Blagoskonov ${ }^{3}$, Julie Barberet ${ }^{1,2}$, Magali Guilleman², Sandrine Daniel ${ }^{4,5}$, Benjamin Tournier ${ }^{6}$, Christine Binquet ${ }^{4,5}$, Cécile Choux ${ }^{1,7}$ and Patricia Fauque ${ }^{1,2^{*}}$ (i)

\begin{abstract}
Background: Testicular germ cell tumor such as seminoma is strongly associated with male reproductive problems commonly associated with the alteration of sperm parameters as described in testicular dysgenesis syndrome. Interestingly, numerous studies have reported that the precursor of germ cell cancer, germ cell neoplasia in situ (GCNIS), present similarities to fetal gonocytes, specifically characterized by global DNA hypomethylation particularly on imprinting sequences. These disorders may have a common origin derived from perturbations of embryonal programming during fetal development. Presently, there is no available information concerning the sperm DNA methylation patterns of testicular cancer patients. For the first time, we evaluated the sperm imprinting of seminoma patients.

A total of 92 cryopreserved sperm samples were included, 31 before seminoma treatment (S): 23 normozoospermic (SN) and 8 oligozoospermic (SO) and 61 sperm controls samples: 31 normozoospermic $(\mathrm{N})$ and 30 oligozoospermic (O). DNA methylation levels of seven differentially methylated regions (DMRs) of imprinted genes [H19/IGF2: IG-DMR (CTCF3 and CTCF6 of H19 gene); IGF2-DMRs (DMR0 and DMR2); MEG3/DLK1:IG-DMR; SNURF:TSS-DMR; KCNQ1OT1:TSS-DMR] were assessed by pyrosequencing. All comparative analyses were adjusted for age.
\end{abstract}

Results: Comparisons of sperm DNA methylation levels between seminoma (S) and normozoospermic $(\mathrm{N})$ samples showed a significant difference for the SNURF sequence $(p=0.017$ ), but after taking into account the sperm parameters, no difference was observed. However, we confirmed a significant association between oligozoospermia $(O)$ and imprinting defects for H19/IGF2-CTCF6 $(p=0.001)$, MEG3/DLK1 $(p=0.017)$, IGF2-DMR2 $(p=0.022)$, and SNURF ( $p=0.032)$ in comparison with control groups (N).

Conclusions: This study highlights the high risk of sperm imprinting defects in cases of oligozoospermia and shows for the first time that seminoma patients with normal spermatogenesis present sperm imprinting integrity. These data suggest a low probability of the involvement of a common imprinting defect in fetal cells leading to both TGCT and subfertility.

Keywords: Testicular germ cell tumor (TGCT), Seminoma, Imprinted genes, Sperm DNA methylation, Testicular dysgenesis syndrome (TDS), Oligozoospermia

\section{Background}

It is now well documented that the incidence of testicular germ cell tumor (TGCT) has been increasing over the past decades, particularly in developed countries [1-4]. It could become a real sanitary problem as recent estimations have predicted that in 2025 around one in 100 men

\footnotetext{
* Correspondence: patricia.fauque@chu-dijon.fr

'Université Bourgogne Franche-Comté-Equipe Génétique des Anomalies du Développement (GAD) INSERM UMR1231, 2 Rue Angélique Ducoudray, F-21000 Dijon, France

${ }^{2} \mathrm{CHU}$ Dijon Bourgogne, Laboratoire de Biologie de la Reproduction-CECOS,

14 rue Gaffarel, F-21000 Dijon, France

Full list of author information is available at the end of the article
}

will be diagnosed with TGCT [3]. Moreover, the risk of TGCT is strongly associated with several male reproductive problems such as cryptorchidism, hypospadias, disorders of sex development, low testosterone levels, and the alteration of sperm parameters [5-9]. The association of various disorders, defined by Skakkebaeck and colleagues as testicular dysgenesis syndrome (TDS) [8], may have a common origin derived from perturbations of fetal programming [9]. Moreover, the unconventional inheritance for TGCT risk both in humans and mice suggest the involvement of epigenetic mechanisms probably through environmental effects [10].

(c) The Author(s). 2018 Open Access This article is distributed under the terms of the Creative Commons Attribution 4.0 International License (http://creativecommons.org/licenses/by/4.0/), which permits unrestricted use, distribution, and reproduction in any medium, provided you give appropriate credit to the original author(s) and the source, provide a link to the Creative Commons license, and indicate if changes were made. The Creative Commons Public Domain Dedication waiver (http://creativecommons.org/publicdomain/zero/1.0/) applies to the data made available in this article, unless otherwise stated. 
Numerous studies have reported that the precursor of germ cell cancer, i.e., germ cell neoplasia in situ (GCNIS) [11], presents similarities to fetal gonocytes, such as cellular, epigenetic, and transcriptomic patterns [12-15]. New insights to epigenetics have showed different genome methylation patterns depending on the types of TGCT [16]. Indeed, contrary to non-seminoma, seminoma cells are characterized by low DNA methylation levels, as found for GCNIS [17-21].

Moreover, TGCT patients present more frequently with subfertility and abnormal spermatogenesis [22]. Interestingly, during the last decade numerous studies have reported abnormal sperm DNA methylation in infertile patients especially for oligozoospermic men [23-34]. These methylation defects occur at imprinted loci (mostly for IGF2 and $H 19$ genes), and promoters regions as well as genome-wide [25, 35-40].

All of these raise the issue of the reproductive health in TGCT context, especially on the imprinting process which takes place in the germline during fetal development.

For the first time, we have addressed the question of sperm DNA methylation patterns in TGCT patients. We chose to specifically investigate seminoma for its epigenetic pattern similar to GCNIS by performing sperm DNA methylation analyses using pyrosequencing technology on seven imprinted genes. From a total of 92 men included in this study, we showed major sperm imprinting defects in seminoma patients with oligozoospermia as well of those observed for oligozoospermic men.

\section{Results}

Our study included 92 sperm samples from men who had cryopreserved sperm: 31 before seminoma treatments (S), and 61 in the context of ART procedures who served as controls [31 normozoospermic $(\mathrm{N})$ and 30 oligozoospermic $(\mathrm{O})$ ]. Among seminoma patients, 23 (74\%) were normozoospermic (SN) and $8(26 \%)$ were oligozoospermic (SO). Patient characteristics and sperm parameters in each group are reported in Table 1. Twelve seminoma patients (38\%) were known to have had fathered before cryopreservation and 21 (81\%) at the time of inclusion, 4 patients had a history of retractile testicles (without cryptorchidism) and 1 presented history of testicular trauma. Concerning $\mathrm{N}$ group patients, $81 \%$ had at least one child at inclusion and none of them presented uro-genital conditions. For oligozoospermic control men (O group), 68\% were known to have fathered at inclusion following ART, 15 (50\%) had urogenital issues including cryptorchidism ( $n=6$ patients), retractile testicles $(n=2)$, varicoceles $(n=1)$, testicular torsion or trauma $(n=3)$, mumps orchitis $(n=1)$, inguinal hernia $(n=2)$. No statistical difference was found between $\mathrm{SN}$ vs $\mathrm{N}$ groups concerning sperm parameters and fertility status (minimum $p=0.135$; Table 1 ).

As expected, in the $\mathrm{N}$ group, high and low sperm DNA methylation levels were observed for paternal and maternal imprinted genes, respectively (Additional file 1: Table S1A). After adjusting for age, significant differences were found between $\mathrm{N}$ vs O groups for H19/IGF2-CTCF6 ( $p=$ 0.001), MEG3/DLK1 ( $p=0.017)$, IGF2-DMR2 $(p=0.022)$,

Table 1 Characteristics of study participants

\begin{tabular}{|c|c|c|c|c|c|}
\hline & $\begin{array}{l}\text { Control } \\
\text { normozoospermic }\end{array}$ & Seminoma Total & $\begin{array}{l}\text { Seminoma } \\
\text { normozoospermic }\end{array}$ & $\begin{array}{l}\text { Seminoma } \\
\text { oligozoospermic }\end{array}$ & $\begin{array}{l}\text { Control } \\
\text { oligozoospermic }\end{array}$ \\
\hline & $\mathrm{N}$ & $\mathrm{S}$ & SN & $\mathrm{SO}$ & $\mathrm{O}$ \\
\hline Number of men & 31 & 31 & 23 & 8 & 30 \\
\hline Age (y) & $37.1+/-5.7^{\mathrm{a}, \mathrm{b}, \mathrm{e}}$ & $32.2+1-6.5^{\mathrm{a}, \mathrm{d}}$ & $32.2+/-6.2^{b}$ & $32.4+/-7.8$ & $32.9+/-4.1^{\mathrm{d}, \mathrm{e}}$ \\
\hline $\begin{array}{l}\text { Urogenital conditions } \\
\text { (no., \%) }\end{array}$ & 0 & $5(16 \%)$ & $2(8 \%)$ & $3(37 \%)$ & $15(50 \%)$ \\
\hline Cryptorchidism & 0 & 0 & 0 & 0 & 6 \\
\hline Others* & 0 & 5 & 2 & 3 & 9 \\
\hline $\begin{array}{l}\text { Concentration } \\
\text { (million/ml, } \pm S D \text { ) }\end{array}$ & $66.0+/-72.3^{a, e}$ & $35.9+/-33.7^{\mathrm{a}, \mathrm{d}}$ & $46.3+/-33.3$ & $6.1+/-4.9$ & $4.5+/-6.4^{\mathrm{d}, \mathrm{e}}$ \\
\hline Count (million, $\pm \mathrm{SD}$ ) & $257.4+/-335.3^{\mathrm{a}, \mathrm{e}}$ & $129.8+/-177.4^{\mathrm{a}, \mathrm{d}}$ & $169.8+/-190.7$ & $14.9+/-12.3$ & $11.6+/-10.2^{\mathrm{d}, \mathrm{e}}$ \\
\hline $\begin{array}{l}\text { Progressive motility } \\
(\%, \pm S D)\end{array}$ & $46.3+/-13.4^{e}$ & $44.4+/-20.1^{d}$ & $50.3+/-15.9$ & $27.5+/-22.3$ & $27.9+/-15.3^{\mathrm{d}, \mathrm{e}}$ \\
\hline $\begin{array}{l}\text { Normal morphology } \\
(\%, \pm S D)\end{array}$ & $31.2+/-17.7^{\mathrm{e}}$ & $32.1+/-18.3^{d}$ & $31.1+/-17.7$ & $36.0+/-21.9^{c}$ & $6.3+1-6.9^{\mathrm{c}, \mathrm{d}, \mathrm{e}}$ \\
\hline Father at inclusion (\%) ${ }^{f}$ & 81 & 81 & 89 & 50 & 68 \\
\hline
\end{tabular}

SD standard deviation, $y$ years

Significant difference between $\mathrm{N}$ and $\mathrm{S}^{\mathrm{a}} ; \mathrm{N}$ and $\mathrm{SN}^{\mathrm{b}} ; \mathrm{SO}$ and $\mathrm{O}^{\mathrm{c}} ; \mathrm{O}$ and $\mathrm{S}^{\mathrm{d}} ; \mathrm{N}$ and $\mathrm{O}^{\mathrm{e}}(p<0.05)$

*Retractile testicles, varicocele, testicular torsion, mumps orchitis, and inguinal hernia

fPercentage according to available data 
and SNURF ( $p=0.032)$ (Figs. 1 and 2, Additional file 1: Table S1B and Additional file 2: Table S2, Additional file 3: Figure S1). The variability of DNA methylation levels was high in the $\mathrm{O}$ group (Fig. 1, Additional file 4: Table S3). Moreover, sperm methylation levels of all $\mathrm{O}$ group patients with history of cryptorchidism were identified as outliers for at least one sequence (Fig. 1).

Concerning seminoma patients (S), after adjusting for age, comparisons of sperm DNA methylation levels between the $\mathrm{S}$ and $\mathrm{N}$ groups showed a significant difference

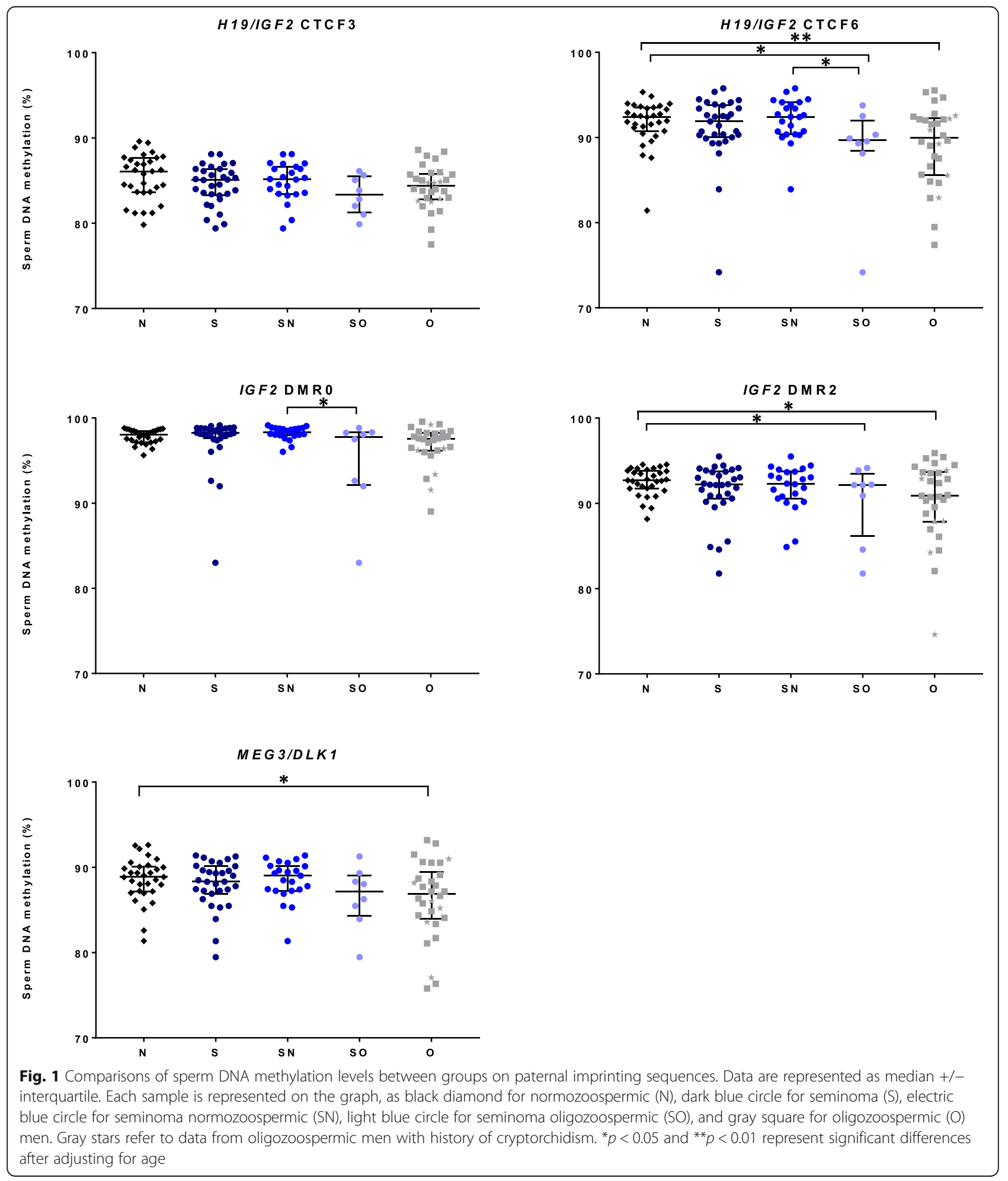




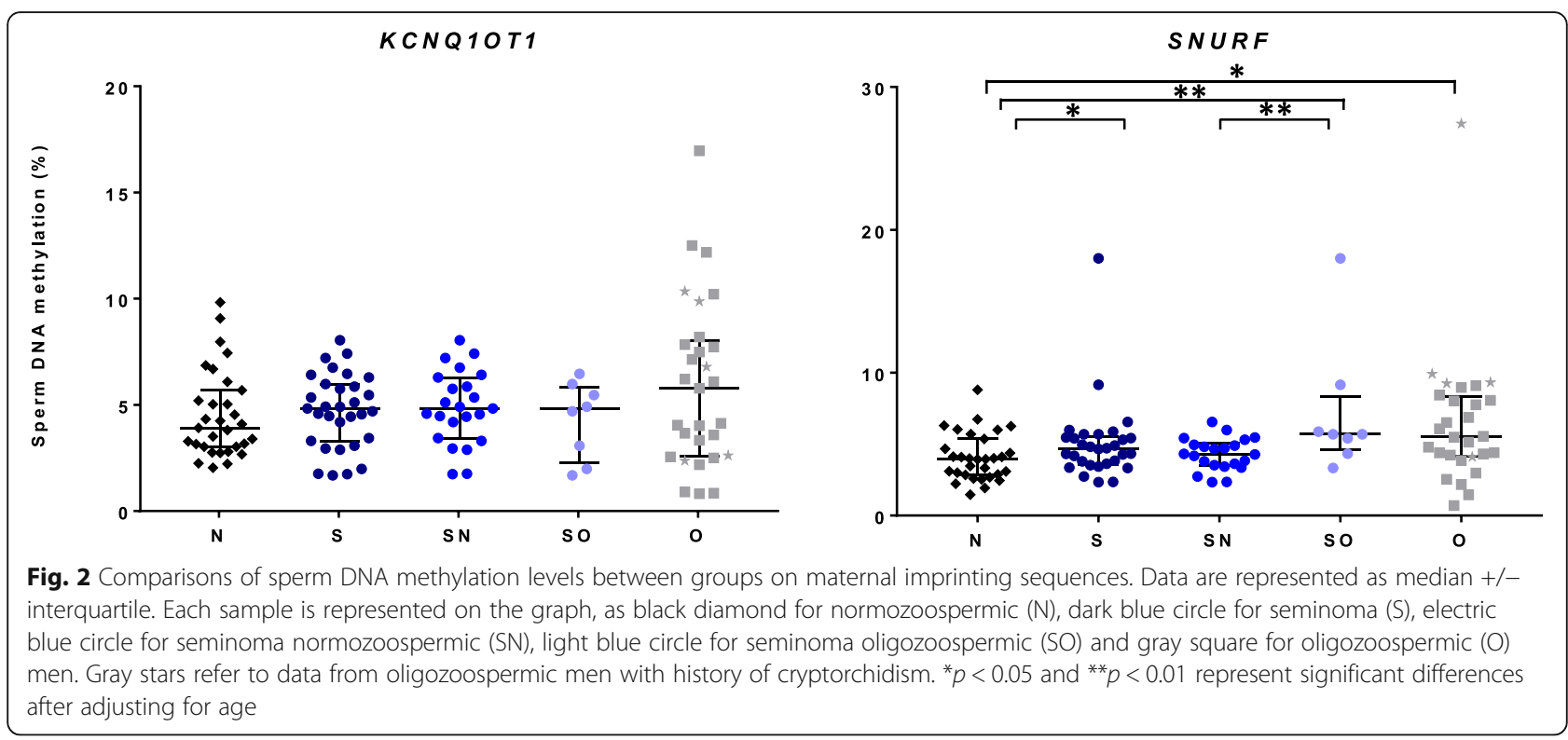

for the SNURF sequence ( $p=0.017)$. However, after taking into account the sperm parameters, no difference was observed for both SN (seminoma normozoospermic men) vs $\mathrm{N}$ and SO (seminoma oligozoospermic men) vs O (Fig. 2, Additional file 1: Table S1B). In contrast, in the SO group, specific imprinting defects were detected for H19/ IGF2-CTCF6 $\quad(p=0.013), \quad$ SNURF $\quad(p=0.001) \quad$ and IGF2-DMR2 $(p=0.019)$ compared to $\mathrm{N}$ group (Figs. 1 and 2, Additional file 1: Table S1B).

\section{Discussion}

To our knowledge, this is the first study to report the analyses of sperm DNA methylation in patients with seminoma. After adjusting for age, imprinting defects on SNURF were detected in the seminoma group in comparison with the normozoospermic controls, but after taking into account sperm parameters, we did not observe any significant difference. Therefore, seminoma patients with normal spermatogenesis appear to maintain sperm imprinting integrity. Moreover, our findings confirmed a strong association between oligozoospermia and imprinting defects (herein, on H19/IGF2, MEG3/ DLK1, and SNURF DMRs for oligozoospermic patients with or without seminoma).

In this study, we chose to compare normozoospermic and oligozoospermic controls because seminoma patients could have altered sperm parameters. Moreover, $40-50 \%$ of TGCT patients present low sperm concentration before cryopreservation [6, 41, 42]. However, in the present study, only $26 \%$ of seminoma patients showed signs of oligozoospermia. This difference could be explained by a drastic selection of samples. Herein, we excluded (1) samples with somatic cell contamination at systematic microscopic control of the preparation of purified spermatozoa,
(2) samples with altered quality of extracted sperm DNA, (3) patients with extreme oligozoospermia.

Our analyses on controls allowed us to confirm imprinted defects in samples with low sperm concentration [33]. As previously reported, we observed altered sperm DNA methylation for oligozoospermic controls in the H19-IGF2, IGF2-DMR2, SNURF, and MEG3/DLK1 DMRs [23, 26].

All these alterations both on maternal and paternal imprinted genes (hyper- and hypomethylation, respectively) observed in "control" cases of deficient spermatogenesis, could be due to failures in erasure/gain of DNA methylation during germ cell development [23]. Moreover, the association of cryptorchidism with sperm imprinting defects observed in the present study may be in favor of the hypothesis of a fetal origin to these defects.

Since the 1990s, most epidemiological trends have reported a decrease of semen parameters in developed countries [43], associated with an increased risk of male reproductive disorders like cryptorchidism, hypospadias, disorders of sex development, and TGCT $[9,44]$. Moreover, given these observations and based on epigenetic findings, environmental influences during fetal life are largely suspected in the occurrence of testicular dysgenesis syndrome (TDS). Indeed, it has been reported in animal models that the exposition to endocrine disruptors during fetal life lead to testicular diseases, sperm parameter alterations, obesity, and sperm epigenetic defects on imprinted genes [45-51]. However, at present, there is no available information about the epigenetic status of the human germ cells in the TDS environment and particularly in TGCT. To address this issue, we performed analyses on sperm both in subfertile patients and in seminoma patients. Notably, seminoma cells presented epigenetic patterns close to GCNIS and were 
characterized by a global DNA hypomethylation, particularly on imprinting sequences [18, 20,21].

We found that seminoma patients with oligozoospermia also presented sperm DNA methylation alterations on imprinted genes. The alterations were quite similar to those observed in oligozoospermic controls.

These observations suggest (1) that spermatozoa in the seminoma environment are not systematically associated with imprinting defects and, (2) a low probability of the involvement of a common imprinting defect in fetal germ cells leading to both TCGT and subfertility.

One hypothesis is that two independent fetal processes could be involved; one in germ cells dedifferentiation leading to GCNIS formation and the second leading to imprinting defects in germ cells. The occurrence of one or the other or both may depend on the time, intensity, and the period of exposition to an inappropriate fetal environment. Another explanation of the increase in sperm parameters alterations in the TGCT context could be the consequences of tumor proliferation and local inflammation.

Indeed, presently emerging evidence highlight the influence of environmental factors on human sperm DNA methylation, notably lifestyle factors [52-56]. As hypothesized by Kobayashi et al., the relation between paternal age and sperm DNA methylation abnormalities could be the memory of cumulative environmental influences over the years [55]. Interestingly, Jenkins and al. used microarray analyses to identify regions which were significantly hypomethylated $(n=139)$ and hypermethylated $(n=8)$ in advanced-age paternal sperm [53]. However, none of the imprinted genes analyzed in our study was identified to be age-susceptible.

Altogether, these results are rather reassuring in regards to the sperm imprinting integrity of seminoma patients as well as their fertility. Indeed, in the present study, $84 \%$ of seminoma patients were known to have fathered at the time of inclusion, in accordance with the few clinical reports [22, 57]. However, there may be epigenetic risks linked to sperm alterations $[6,41,42]$. As most seminoma patients are young and have not fathered at the time of sperm cryopreservation (herein 62\%), the question on the association with potential imprinting defects and their consequences for the conceptus is particularly crucial. Indeed, it is already known that assisted reproductive technologies (IVF or ICSI), widely used for men with oligozoospermia, are associated with increased incidences of rare imprinting disorders, especially Beckwith-Widemann syndrome, Angelman syndrome and Silver-Russell syndrome. The technique itself could be involved [58], but the use of sperm with preexisting imprinting defects is not excluded. Moreover, a correlation between sperm methylation alterations and adverse pregnancy outcomes have also been reported $[26,55,59,60]$. However, these germ cell DNA methylation defects could have consequences later in life, leading to various diseases in adulthood such as cardiovascular diseases or cancers $[61,62]$.

There are some limitations in this study. First, although somatic cells were not observed during microscopic control of all sperm preparations, an improbable somatic cell contamination cannot be fully excluded. Nevertheless, we reported comparable sperm DNA methylation levels for oligozoospermic men as observed in previous studies $[23,56]$. Second, the pyrosequencing method allowed us to analyze DNA methylation at only a few CpGs per DMR (between 3 and 18). Even though it would have been interesting to perform analyses at larger scale, the resolution in imprinted regions would have been lower. And third, as previously discussed, a lack of information concerning the potential confounding factors could modify the results, though the adjustment for age limited this effect.

Overall, it still remains to be determined whether seminoma patients with alterations to spermatogenesis can return to spermatogenesis and DNA methylation levels comparable to the normozoospermic and fertile control population on the tested sequences and also on large scale.

\section{Conclusions}

This study highlights the high risk of sperm imprinting defects (both in paternal and maternal DMRs) in cases of oligozoospermia and shows that seminoma patients with normal spermatogenesis presented sperm imprinting integrity. These novel data disprove the idea of a common fetal imprinting defect in germ cells leading to both CGNIS and subfertility. Environmental factors are strongly suspected and could act throughout life, even if the fetal period is presumptively more at risk for the development of severe chronic diseases.

Our findings shed light onto the need to set up epigenetic explorations for men with spermatogenesis deficiencies.

\section{Methods}

\section{Aim, design, and setting of the study}

To assess the sperm imprinted pattern of seminoma patients, a total of 92 sperm samples were included 31 before seminoma treatment (S) and 61 in the context of ART procedures who served as controls: 31 normozoospermic $(\mathrm{N})$ and 30 oligozoospermic $(\mathrm{O})$. Among seminoma patients $(\mathrm{S})(n=31)$, we established two subgroups according to their sperm parameters: normozoospermic seminoma patients $(\mathrm{SN})(n=23)$ and oligozoospermic seminoma patients $(\mathrm{SO})(n=8)$. Seminoma samples were selected according to the histology analyses, and only cryopreserved sperm from pure seminoma patients were included in the study. 
We specifically selected imprinted genes which are known to be perturbed in altered spermatogenesis [23, 33 and/or in a context of infertility [24, 27, 33]. DNA methylation levels of seven differentially methylated regions (DMRs) of imprinted genes (H19/IGF2:IG-DMR: CTCF3 and CTCF6 of $H 19$ gene and the DMR0 and DMR2 of IGF2 gene; GTL2-DMR; SNURF:TSS-DMR; KCNQ1OT1:TSS-DMR) were assessed by pyrosequencing. All analyses were performed after adjusting for age and compared according to the sperm parameters.

\section{Subjects and samples}

Cryopreserved sperm samples from 92 patients were collected from two CECOS centers (Centre d'Etude et de Conservation des Oeufs et du Sperm) in Dijon and Besançon, France. According to French law, patients who have cryopreserved sperm and want to dispose of it can choose to donate their sperm straws to research programs. All volunteer patients provided written informed consent as approved by the Ethics Committee of the University and the state medical board (2016 PHRCI-16-046, NCT03262207). Thirty-one samples were obtained from patients who cryopreserved their sperm before seminoma treatments (S), 30 from oligozoospermic $(\mathrm{O})$ patients who underwent undergone fertility treatments, and 31 from normozoospermic patients (N) who cryopreserved before vasectomy or egg donation attempts. In all groups, samples were selected according to sperm parameters with at least $0.5 \mathrm{M} / \mathrm{ml}$ for sperm concentration, and no leucocytes or others cells identified before cryopreservation in order to limit diploid cell contamination.

\section{Sperm cryopreservation protocol}

After 30 min of liquefaction, fresh ejaculate was diluted 1:1 in sperm cryoprotector medium (Spermfreeze $^{\mathrm{m}}$, Vitrolife) and filled in straws. Samples were frozen using programming controlled rate freezer (Minicool LC40 Air liquid or Kryo 560-Planer PLC) and cooled from $4{ }^{\circ} \mathrm{C}$ to $-8{ }^{\circ} \mathrm{C}$ at a rate of $-5{ }^{\circ} \mathrm{C} / \mathrm{min}$, then at a rate of $-10{ }^{\circ} \mathrm{C} / \mathrm{min}$ to $-25{ }^{\circ} \mathrm{C}$ and finally at rate of $25{ }^{\circ} \mathrm{C} / \mathrm{min}$ to $-140{ }^{\circ} \mathrm{C}$. Samples were then plunged into nitrogen for storage.

\section{Thawing procedure and sperm preparation}

Thawing was performed in an incubator system at $37^{\circ} \mathrm{C}$ during $7 \mathrm{~min}$. Spermatozoa were purified using a Percoll gradient with two concentration layers (90/45\%, PureSperm, JCD) to remove lymphocytes, epithelial cells, cell debris, bacteria, abnormal spermatogenic cells, and seminal fluid. Sperm purity was controlled by inverted light microscopy and samples were then stored at $-80{ }^{\circ} \mathrm{C}$ until further use.
Measurements of sperm count, sperm motility, and sperm morphology were assessed in accordance with the World Health organization (WHO) guidelines both before and after freezing.

\section{DNA extraction}

Sperm DNA was extracted according to the modified protocol described by Marques et al. [28]. Briefly, sperm pellets were overlaid with $500 \mu \mathrm{l}$ of lysis solution (LS) containing $10 \mathrm{mM}$ Tris- $\mathrm{HCl} \mathrm{pH} 7.5,10 \mathrm{mM}$ EDTA, $0.2 \%$ SDS, $50 \mathrm{mM} \mathrm{NaCl}, 1 \mathrm{mM}$ DTT, and $0.2 \mathrm{mg} / \mathrm{ml}$ proteinase $\mathrm{K}$ (Fermentas) and incubated overnight at $55^{\circ} \mathrm{C}$. Sperm DNA was isolated by standard phenol chloroform extraction. DNA was precipitated using cold ethanol (Sigma-Aldrich), washed, and solubilized in water. All DNA samples were quantified/qualified using a Nanodrop Spectrophotometer (Invitrogen). Sperm DNA samples were included in the study if the ratio DO260/280 was between 1.8 and 2 and the DNA concentration above $50 \mathrm{ng} / \mu \mathrm{l}$.

\section{DNA methylation analyses}

DNA methylation levels of seven differentially methylated regions (DMRs) of imprinted genes [H19/IGF2: IG-DMR (CTCF3 and CTCF6 of $H 19$ gene); IGF2-DMRs (DMR0 and DMR2); MEG3/DLK1: IG-DMR; SNURF:TSS-DMR; KCNQ1OT1:TSS-DMR] were assessed by pyrosequencing after sodium bisulfite DNA treatment. Genomic DNA (500 ng) was modified by sodium bisulfite treatment using the EpiTect kit (Qiagen). Bisulfite-treated DNA (25 ng) was subsequently used as the template for PCR amplification prior to pyrosequencing as previously described in Bruno et al., 2015 [63]. Primers are available in Additional file 5: Table S4. Pyrosequencing reactions were performed in the PyroMark Q24 System (Qiagen) with the PyroGold SQA reagent kit according to the manufacturer's instructions (Pyrosequencing AB, Uppsala, Sweden). The biotinylated PCR products were purified and denatured using the Pyrosequencing Vacuum Prep Tool (Qiagen). Pyrosequencing was performed on a Pyrosequencer Q24 (Qiagen). The DNA methylation level was calculated as the ratio of the $\mathrm{C}$ to $\mathrm{T}$ peaks at a given $\mathrm{CpG}$ site in pyrograms using Pyromark Q24 Software v.2.0.6 (Qiagen). Considering the presence of SNPs and high variability on one CpG of H19/IGF2-CTCF6 (no. 5) and two CpGs of IGF2-DRMR2 (no. 8 and 9), these CpGs were not considered for quantitative methylation analysis.

\section{Statistical analyses}

Continuous variables are described as median and interquartile range (IQR) or mean \pm standard error of the mean (SEM) according to their distribution. Categorical variables are described using percentages. Baseline demographic and clinical characteristics were compared among the five groups depending on cryopreservation indication 
and sperm parameters. The distribution of continuous variables were compared using Mann-Whitney or Kruskal-Wallis tests and the ones of categorical variables using chi-square test or Fisher exact test when appropriate. Values that did not lie within the interquartile range and above 75th percentile for paternal imprinted genes or below the 25th percentile for the maternal imprinted genes were defined as outliers. Multivariate linear regression analyses were used to adjust all estimated for age. A log transformation of DNA methylation levels was applied to normalize their distribution. All statistical analyses were performed with SAS software, v9.4 (SAS Institute Inc., USA). A two-tailed $p<0.05$ was considered significant.

\section{Additional files}

\section{Additional file1: Table S1. Sperm DNA methylation analyses on} imprinted genes for each analyzed group. (DOCX $28 \mathrm{~kb}$ )

Additional file 2: Table S2. Comparison of sperm DNA methylation between oligozoospermic controls $(\mathrm{O})$ and normozoospermic controls (N), after adjusting for age, for each $\mathrm{CpG}$ site of the deregulated imprinted genes. (DOCX $29 \mathrm{~kb}$ )

Additional file 3: Figure S1. Comparisons of sperm DNA methylation levels between normozoospermic and oligozoospermic controls at each $\mathrm{CpG}$ of the specific altered imprinted sequences detected in the study. Methylation levels at each $\mathrm{CpG}$ position are expressed in percentage as mean \pm SEM. ${ }^{*} p<0.05$ and ${ }^{* *} p<0.01$ significant differences after adjusting for age. $\mathrm{N}$ : normozoospermic (black square), O oligozoospermic (gray circle). (DOCX $346 \mathrm{~kb}$ )

Additional file 4: Table S3. Relative standard deviation (RSD) of sperm DNA methylation on imprinted genes for control groups (normozoospermic and oligozoospermic). (DOCX $15 \mathrm{~kb}$ )

Additional file 5: Table S4. Primers for pyrosequencing [23, 63, 64]. (DOCX $28 \mathrm{~kb}$ )

\section{Abbreviations}

ART: Assisted reproductive technology; DMR: Differentially methylated regions; GCNIS: Germ cell neoplasia in situ; ICSI: Intracytoplasmic sperm injection; IVF: In vitro fertilization; N: Normozoospermic control;

O: Oligozoospermic control; S: Seminoma patient; SN: Normozoospermic seminoma patient; SO: Oligozoospermic seminoma patient; TDS: Testicular dysgenesis syndrome; TGCT: Testicular germ cell tumor

\section{Acknowledgements}

The authors thank the technicians from the assisted reproductive technologies unit of Dijon Hospital for their implication in this project. We thank Maud Carpentier of the "Direction de la Recherche Clinique et de I'Innovation" of Dijon University Hospital for the promotion and the management of the study. We thank Suzanne Rankin for her help in writing the manuscript.

\section{Funding}

The independent study was supported by a grant from the French Ministry of Health (2016, PHRCI-16-046) and a grant from the "Conseil Régional de Bourgogne Franche-Comté" and the "CHU Dijon Bourgogne" (2016, AOI).

\section{Availability of data and materials}

All data generated or analyzed during this study are included in this published article and its supplementary information files.

\section{Authors' contributions}

$\mathrm{CBr}, \mathrm{CBi}$, and PF contributed to the design of the study and to the analysis and interpretation of data. $\mathrm{CBr}, \mathrm{MG}$, and $\mathrm{OB}$ recruited the patients and contributed to the acquisition of the data. $\mathrm{CBr}, \mathrm{MG}, \mathrm{JB}, \mathrm{TB}$, and $\mathrm{CC}$ were involved in experiments.
CBi and SD performed statistical analyses. CBr and PF drafted the manuscript. All authors give their final approval of the version to be published.

Ethics approval and consent to participate

All volunteer patients provided written informed consent as approved by the Ethics Committee of the University and the state medical board (2016 PHRCl-16-046, NCT03262207).

\section{Consent for publication}

Not applicable.

\section{Competing interests}

The authors declare that they have no competing interests.

\section{Publisher's Note}

Springer Nature remains neutral with regard to jurisdictional claims in published maps and institutional affiliations.

\section{Author details}

'Université Bourgogne Franche-Comté-Equipe Génétique des Anomalies du Développement (GAD) INSERM UMR1231, 2 Rue Angélique Ducoudray, F-21000 Dijon, France. ${ }^{2} \mathrm{CHU}$ Dijon Bourgogne, Laboratoire de Biologie de la Reproduction-CECOS, 14 rue Gaffarel, F-21000 Dijon, France. ${ }^{3} \mathrm{CHRU}$ Besançon, Service de Biologie et de Médecine de la Reproduction-CECOS, 3 Boulevard Fleming, F-25030 Besançon, France. ${ }^{4} \mathrm{CHU}$ Dijon Bourgogne, Centre d'Investigation Clinique, Module Epidémiologie Clinique/Essais

Cliniques (CIC-EC), 7 boulevard Jeanne d'Arc, F-21000 Dijon, France.

${ }^{5}$ Université Bourgogne Franche-Comté-INSERM, CIC1432, Module Épidémiologie Clinique, 7 boulevard Jeanne d'Arc, F-21000 Dijon, France.

${ }^{6} \mathrm{CHU}$ Dijon Bourgogne, Service de Pathologie, 14 rue Gaffarel, F-21000 Dijon, France. ${ }^{7} \mathrm{CHU}$ Dijon Bourgogne, Service de Gynécologie-Obstétrique, 14 rue Gaffarel, F-21000 Dijon, France.

Received: 5 June 2018 Accepted: 4 October 2018

Published online: 19 October 2018

\section{References}

1. McGlynn KA, Devesa SS, Sigurdson AJ, Brown LM, Tsao L, Tarone RE. Trends in the incidence of testicular germ cell tumors in the United States. Cancer. 2003;97:63-70

2. Purdue MP, Devesa SS, Sigurdson AJ, McGlynn KA. International patterns and trends in testis cancer incidence. Int J Cancer. 2005:115:822-7.

3. Le Cornet C, Lortet-Tieulent J, Forman D, Béranger R, Flechon A, Fervers B, et al. Testicular cancer incidence to rise by $25 \%$ by 2025 in Europe? Modelbased predictions in 40 countries using population-based registry data. Eur J Cancer Oxf Engl 1990. 2014;50:831-9.

4. Znaor A, Lortet-Tieulent J, Jemal A, Bray F. International variations and trends in testicular cancer incidence and mortality. Eur Urol. 2014:65:1095-106.

5. Jørgensen A, Lindhardt Johansen M, Juul A, Skakkebaek NE, Main KM, Rajpert-De ME. Pathogenesis of germ cell neoplasia in testicular dysgenesis and disorders of sex development. Semin Cell Dev Biol. 2015;45:124-37.

6. Mackenna A, Crosby J, Huidobro C, Correa E, Duque G. Semen quality before cryopreservation and after thawing in 543 patients with testicular cancer. JBRA Assist Reprod. 2017;21:31-4.

7. Serrano $T$, Chevrier $C$, Multigner $L$, Cordier $S$, Jégou B. International geographic correlation study of the prevalence of disorders of male reproductive health. Hum Reprod Oxf Engl. 2013;28:1974-86.

8. Skakkebaek NE, Rajpert-De Meyts E, Main KM. Testicular dysgenesis syndrome: an increasingly common developmental disorder with environmental aspects. Hum Reprod Oxf Engl. 2001;16:972-8.

9. Skakkebaek NE, Rajpert-De Meyts E, Buck Louis GM, Toppari J, Andersson A-M, Eisenberg ML, et al. Male reproductive disorders and fertility trends: influences of environment and genetic susceptibility. Physiol Rev. 2016;96:55-97.

10. Carouge D, Blanc V, Knoblaugh SE, Hunter RJ, Davidson NO, Nadeau JH. Parent-of-origin effects of $\mathrm{A} 1 \mathrm{CF}$ and $\mathrm{AGO} 2$ on testicular germ-cell tumors, testicular abnormalities, and fertilization bias. Proc Natl Acad Sci U S A. 2016; 113:E5425-33.

11. Rajpert-De Meyts E, Nielsen JE, Skakkebaek NE, Almstrup K. Diagnostic markers for germ cell neoplasms: from placental-like alkaline phosphatase to micro-RNAs. Folia Histochem Cytobiol. 2015;53:177-88. 
12. Korkola JE, Houldsworth J, Dobrzynski D, Olshen AB, Reuter VE, Bosl GJ, et al. Gene expression-based classification of nonseminomatous male germ cell tumors. Oncogene. 2005;24:5101-7.

13. Oosterhuis JW, Looijenga LHJ. Testicular germ-cell tumours in a broader perspective. Nat Rev Cancer. 2005;5:210-22.

14. Sonne SB, Almstrup K, Dalgaard M, Juncker AS, Edsgard D, Ruban L, et al. Analysis of gene expression profiles of microdissected cell populations indicates that testicular carcinoma in situ is an arrested gonocyte. Cancer Res. 2009;69:5241-50.

15. Sperger JM, Chen X, Draper JS, Antosiewicz JE, Chon CH, Jones SB, et al. Gene expression patterns in human embryonic stem cells and human pluripotent germ cell tumors. Proc Natl Acad Sci U S A. 2003;100:13350-5.

16. Kristensen DG, Skakkebæk NE, Rajpert-De Meyts E, Almstrup K. Epigenetic features of testicular germ cell tumours in relation to epigenetic characteristics of foetal germ cells. Int J Dev Biol. 2013;57:309-17.

17. Almstrup K, Nielsen JE, Mlynarska O, Jansen MT, Jørgensen A, Skakkebæk NE, et al. Carcinoma in situ testis displays permissive chromatin modifications similar to immature foetal germ cells. Br J Cancer. 2010;103:1269-76.

18. Brait M, Maldonado L, Begum S, Loyo M, Wehle D, Tavora FF, et al. DNA methylation profiles delineate epigenetic heterogeneity in seminoma and non-seminoma. Br J Cancer. 2012;106:414-23.

19. Netto GJ, Nakai Y, Nakayama M, Jadallah S, Toubaji A, Nonomura N, et al. Global DNA hypomethylation in intratubular germ cell neoplasia and seminoma, but not in nonseminomatous male germ cell tumors. Mod Pathol Off J U S Can Acad Pathol Inc. 2008;21:1337-44.

20. Smiraglia DJ, Szymanska J, Kraggerud SM, Lothe RA, Peltomäki P, Plass C. Distinct epigenetic phenotypes in seminomatous and nonseminomatous testicular germ cell tumors. Oncogene. 2002;21:3909-16.

21. van der Zwan YG, Rijlaarsdam MA, Rossello FJ, Notini AJ, de Boer S, Watkins DN, et al. Seminoma and embryonal carcinoma footprints identified by analysis of integrated genome-wide epigenetic and expression profiles of germ cell cancer cell lines. PLoS One. 2014;9:e98330.

22. Depalo R, Falagario D, Masciandaro P, Nardelli C, Vacca MP, Capuano P, et al. Fertility preservation in males with cancer: 16-year monocentric experience of sperm banking and post-thaw reproductive outcomes. Ther Adv Med Oncol. 2016:8:412-20.

23. Boissonnas CC, Abdalaoui HE, Haelewyn V, Fauque P, Dupont JM, Gut I, et al. Specific epigenetic alterations of IGF2-H19 locus in spermatozoa from infertile men. Eur J Hum Genet EJHG. 2010;18:73-80.

24. Hammoud SS, Purwar J, Pflueger C, Cairns BR, Carrell DT. Alterations in sperm DNA methylation patterns at imprinted loci in two classes of infertility. Fertil Steril. 2010;94:1728-33.

25. Houshdaran S, Cortessis VK, Siegmund K, Yang A, Laird PW, Sokol RZ. Widespread epigenetic abnormalities suggest a broad DNA methylation erasure defect in abnormal human sperm. PLoS One. 2007;2:e1289.

26. Kobayashi H, Sato A, Otsu E, Hiura H, Tomatsu C, Utsunomiya T, et al. Aberrant DNA methylation of imprinted loci in sperm from oligospermic patients. Hum Mol Genet. 2007;16:2542-51.

27. Laurentino S, Beygo J, Nordhoff V, Kliesch S, Wistuba J, Borgmann J, et al. Epigenetic germline mosaicism in infertile men. Hum Mol Genet. 2015;24:1295-304.

28. Marques CJ, Carvalho F, Sousa M, Barros A. Genomic imprinting in disruptive spermatogenesis. Lancet Lond Engl. 2004;363:1700-2.

29. Marques CJ, Costa P, Vaz B, Carvalho F, Fernandes S, Barros A, et al. Abnormal methylation of imprinted genes in human sperm is associated with oligozoospermia. Mol Hum Reprod. 2008;14:67-74.

30. Montjean D, Ravel C, Benkhalifa M, Cohen-Bacrie P, Berthaut I, Bashamboo $A$, et al. Methylation changes in mature sperm deoxyribonucleic acid from oligozoospermic men: assessment of genetic variants and assisted reproductive technology outcome. Fertil Steril. 2013;100:1241-7.

31. Montjean D, Zini A, Ravel C, Belloc S, Dalleac A, Copin H, et al. Sperm globa DNA methylation level: association with semen parameters and genome integrity. Andrology. 2015;3:235-40.

32. Poplinski A, Tüttelmann F, Kanber D, Horsthemke B, Gromoll J. Idiopathic male infertility is strongly associated with aberrant methylation of MEST and IGF2/H19 ICR1. Int J Androl. 2010;33:642-9.

33. Santi D, De Vincentis S, Magnani E, Spaggiari G. Impairment of sperm DNA methylation in male infertility: a meta-analytic study. Andrology. 2017;5:695-703.

34. Sato A, Hiura H, Okae H, Miyauchi N, Abe Y, Utsunomiya T, et al. Assessing loss of imprint methylation in sperm from subfertile men using novel methylation polymerase chain reaction Luminex analysis. Fertil Steril. 2011; 95:129-34.e1-4.
35. Du Y, Li M, Chen J, Duan Y, Wang X, Qiu Y, et al. Promoter targeted bisulfite sequencing reveals DNA methylation profiles associated with low sperm motility in asthenozoospermia. Hum Reprod Oxf Engl. 2016:31:24-33.

36. Jenkins TG, Aston Kl, Meyer TD, Hotaling JM, Shamsi MB, Johnstone EB, et al. Decreased fecundity and sperm DNA methylation patterns. Fertil Steril. 2016;105:51-57.e1-3.

37. Li B, Li J, Xiao X, Ma Y, Wang J, Liang X, et al. Altered DNA methylation patterns of the $\mathrm{H} 19$ differentially methylated region and the DAZL gene promoter are associated with defective human sperm. PLoS One. 2013;8:e71215.

38. Pacheco SE, Houseman EA, Christensen BC, Marsit CJ, Kelsey KT, Sigman M, et al. Integrative DNA methylation and gene expression analyses identify DNA packaging and epigenetic regulatory genes associated with low motility sperm. PLoS One. 2011;6:e20280.

39. Urdinguio RG, Bayón GF, Dmitrijeva M, Toraño EG, Bravo C, Fraga MF, et al. Aberrant DNA methylation patterns of spermatozoa in men with unexplained infertility. Hum Reprod Oxf Engl. 2015:30:1014-28.

40. Wu W, Shen O, Qin Y, Niu X, Lu C, Xia Y, et al. Idiopathic male infertility is strongly associated with aberrant promoter methylation of methylenetetrahydrofolate reductase (MTHFR). PLoS One. 2010;5:e13884.

41. Auger J, Sermondade N, Eustache F. Semen quality of 4480 young cancer and systemic disease patients: baseline data and clinical considerations. Basic Clin Androl. 2016;26:3.

42. Rives N, Walschaerts M, Setif V, Hennebicq S, Saias J, Brugnon F, et al. Sperm aneuploidy after testicular cancer treatment: data from a prospective multicenter study performed within the French Centre d'Étude et de Conservation des Oeufs et du Sperme network. Fertil Steril. 2017;107:580-588.e1.

43. Levine $H$, Jørgensen N, Martino-Andrade A, Mendiola J, Weksler-Derri D, Mindlis I, et al. Temporal trends in sperm count: a systematic review and meta-regression analysis. Hum Reprod Update. 2017;23: 646-59.

44. Tvrda E, Agarwal A, Alkuhaimi N. Male reproductive cancers and infertility: a mutual relationship. Int J Mol Sci. 2015;16:7230-60.

45. Guerrero-Bosagna C, Covert TR, Haque MM, Settles M, Nilsson EE, Anway $M D$, et al. Epigenetic transgenerational inheritance of vinclozolin induced mouse adult onset disease and associated sperm epigenome biomarkers. Reprod Toxicol. 2012;34:694-707.

46. Kläver R, Sánchez V, Damm OS, Redmann K, Lahrmann E, SandhoweKlaverkamp R, et al. Direct but no transgenerational effects of Decitabine and Vorinostat on male fertility. Ward WS, editor. PLoS One. 2015;10:e0117839.

47. Manikkam M, Tracey R, Guerrero-Bosagna C, Skinner MK. Dioxin (TCDD) induces epigenetic transgenerational inheritance of adult onset disease and sperm epimutations. PLoS One. 2012;7:e46249.

48. Manikkam M, Tracey R, Guerrero-Bosagna C, Skinner MK. Plastics derived endocrine disruptors (BPA, DEHP and DBP) induce epigenetic transgenerational inheritance of obesity, reproductive disease and sperm epimutations. PLoS One. 2013;8:e55387.

49. Manikkam M, Haque MM, Guerrero-Bosagna C, Nilsson EE, Skinner MK. Pesticide Methoxychlor promotes the epigenetic transgenerational inheritance of adult-onset disease through the female germline. Ward WS, editor. PLoS One. 2014;9:e102091.

50. Skinner MK, Manikkam M, Tracey R, Guerrero-Bosagna C, Haque M, Nilsson EE. Ancestral dichlorodiphenyltrichloroethane (DDT) exposure promotes epigenetic transgenerational inheritance of obesity. BMC Med. 2013;11:228. https://doi.org/10.1186/1741-7015-11-228.

51. Stouder C, Paoloni-Giacobino A. Transgenerational effects of the endocrine disruptor vinclozolin on the methylation pattern of imprinted genes in the mouse sperm. Reprod Camb Engl. 2010;139:373-9.

52. Finegersh A, Rompala GR, Martin DIK, Homanics GE. Drinking beyond a lifetime: new and emerging insights into paternal alcohol exposure on subsequent generations. Alcohol. 2015;49:461-70.

53. Jenkins TG, Aston Kl, Pflueger C, Cairns BR, Carrell DT. Age-associated sperm DNA methylation alterations: possible implications in offspring disease susceptibility. PLoS Genet. 2014;10:e1004458.

54. Jenkins TG, James ER, Alonso DF, Hoidal JR, Murphy PJ, Hotaling JM, et al. Cigarette smoking significantly alters sperm DNA methylation patterns. Andrology. 2017:5:1089-99.

55. Kobayashi N, Miyauchi N, Tatsuta N, Kitamura A, Okae H, Hiura H, et al. Factors associated with aberrant imprint methylation and oligozoospermia. Sci Rep. 2017;7:42336. 
56. Soubry A, Guo L, Huang Z, Hoyo C, Romanus S, Price T, et al. Obesityrelated DNA methylation at imprinted genes in human sperm: results from the TIEGER study. Clin Epigenetics. 2016;8:51.

57. Gunnes MW, Lie RT, Bjørge T, Ghaderi S, Ruud E, Syse A, et al. Reproduction and marriage among male survivors of cancer in childhood, adolescence and young adulthood: a national cohort study. Br J Cancer. 2016;114:348-56.

58. Choux C, Binquet C, Carmignac V, Bruno C, Chapusot C, Barberet J, et al. The epigenetic control of transposable elements and imprinted genes in newborns is affected by the mode of conception: ART versus spontaneous conception without underlying infertility. Hum Reprod. 2018;33:331-40.

59. Ankolkar M, Patil A, Warke H, Salvi V, Kedia Mokashi N, Pathak S, et al. Methylation analysis of idiopathic recurrent spontaneous miscarriage cases reveals aberrant imprinting at H19 ICR in normozoospermic individuals. Fertil Steril. 2012;98:1186-92.

60. Benchaib M, Braun V, Ressnikof D, Lornage J, Durand P, Niveleau A, et al. Influence of global sperm DNA methylation on IVF results. Hum Reprod Oxf Engl. 2005;20:768-73.

61. Elia L, Condorelli G. RNA (Epi)genetics in cardiovascular diseases. J Mol Cell Cardiol. 2015;89:11-6.

62. Gluckman PD, Hanson MA. Living with the past: evolution, development, and patterns of disease. Science. 2004;305:1733-6.

63. Bruno C, Carmignac V, Netchine I, Choux C, Duffourd Y, Faivre L, et al. Germline correction of an epimutation related to Silver-Russell syndrome. Hum Mol Genet. 2015;24:3314-21.

64. Rancourt RC, Harris HR, Michels KB. Methylation levels at imprinting control regions are not altered with ovulation induction or in vitro fertilization in a birth cohort. Hum Reprod. 2012;27:2208-16.

Ready to submit your research? Choose BMC and benefit from:

- fast, convenient online submission

- thorough peer review by experienced researchers in your field

- rapid publication on acceptance

- support for research data, including large and complex data types

- gold Open Access which fosters wider collaboration and increased citations

- maximum visibility for your research: over $100 \mathrm{M}$ website views per year

At $\mathrm{BMC}$, research is always in progress.

Learn more biomedcentral.com/submissions 